\title{
Stimulatory and Toxic Effects of Neurotransmitters on the lux Operon-Dependent Bioluminescence of Escherichia coli K12 TGI
}

\author{
Elena V. Sorokina ${ }^{1}$, Ilya R. Vodolazov ${ }^{2}$ and Alexander V. Oleskin ${ }^{2, *}$ \\ ${ }^{1}$ Department of Microbiology, Faculty of Biology, Lomonosov Moscow State University, Russia \\ ${ }^{2}$ Department of General Ecology, Faculty of Biology, Lomonosov Moscow State University, Russia
}

\begin{abstract}
Background: The normal functioning of the brain requires neuromediators, i.e., substances that transmit messages between nervous cells. Neurochemicals also function as signals that are involved in communication among the microorganisms that inhabit the human organism. While the impact of "classical" neurotransmitters including catecholamines, serotonin, and histamine on microorganisms has been investigated in a number of recent publications, this work provides evidence for the stimulatory and inhibitory (toxic) effects of some other important neurochemicals that have not received sufficient attention in the literature.

Methods: The biosensor was based on a GM Escherichia coli K12 strain (TGI) that contained the lux operon of the luminescent soil bacterium Photorhabdus luminescencens ZMI. The biosensor was exposed to the action of the tested neurotransmitters for 15 mins to $144 \mathrm{hrs}$. The intensity of bacterial luminescence (counts / second) was monitored in the control and the experimental samples with an 1251 BioOrbit luminometer (Finland).

Results: Neurochemicals such as putrescine, acetylcholine, taurin, and indole were found to stimulate, at low concentrations $(0.1-10 \mu \mathrm{M})$, the luminescence of the strain E. coli K12 TGI containing the lux operon from Photorhabdus luminescencens ZMI. At higher concentrations, putrescine, taurin, and indole exerted a weak toxic influence, i.e. they marginally attenuated the luminescence of $E$. coli K12 TGI.

Conclusions: Based on the data obtained, a regulatory, presumably receptor-dependent, effect is exerted by the tested neurochemicals on the bacterium $E$. coli $\mathrm{K} 12 \mathrm{TGI}$, in an analogy to their impact on nervous, immune, and other specialized types of eukaryotic cells. However, high neurochemical concentrations are likely to produce nonspecific effects on the bacterial luciferase system and/or on membrane phosphorylation.
\end{abstract}

Keywords: Biotesting, bacterial luminescence, toxicity, neurochemicals, biogenic amines, amino acids.

\section{INTRODUCTION}

The brain is the central regulator of human neuropsychological processes and social behavior. Its normal functioning requires neurotransmitters, i.e., substances that transmit messages between nervous cells. Research on the role of these neuroactive substances in intercellular communication and in the interaction between the microbiota and the host organism forms a part of the field called human microecology. The issue concerning the functional role of amine and amino acid neurotransmitters in microbial systems has recently been addressed in studies conducted by several research teams, including those of Prof. Mark Lyte (lowa State University, USA), Prof. G. Fraikin and Prof. A. Oleskin (Faculty of Biology, Moscow State University) [1-6]. It was established that biogenic amines, such as catecholamines (norepinephrine, epinephrine, and dopamine) produce a strong stimulatory effect on the growth of a large number of microorganisms [7-10]. Interestingly, norepinephrine, as well as serotonin and histamine,

*Address correspondence to this author at the Department of General Ecology, School of Biology, MV Lomonosov Moscow State University, Russia; Tel: +7-903-507-2258; E-mail: aoleskin@rambler.ru

ISSN: 2223-3806 / E-ISSN: 1927-5951/19 stimulate cell aggregation, the initial stage of biofilm formation, in a non-pathogenic strain of $E$. coli [6]. However, the development of this non-pathogenic strain is more significantly stimulated by serotonin and especially by histamine than by catecholamines $[5,6]$. In Pseudomonas aeruginosa, serotonin behaves as the pheromone of the QS-system las/R. It enhances virulence and biofilm formation both in vitro and in vivo [11].

Microbial cells produce their own neurochemicals, which were detected by high-performance liquid chromatography in a variety of pro- and eukaryotic microorganisms. These measurements were originally performed during the late exponential growth phase of microbial cultures [12]. Subsequently, the growth dynamics of neurochemical synthesis and release into the medium was investigated in the bacteria $E$. coli and Bacillus cereus, as well as the yeast Sacchromyces cerevisiae [13-15]. Recently, similar studies on the intra- and extracellular concentrations of amine neurochemicals have been conducted in a number of lactobacilli and bifidobacteria [16-19].

Despite the data obtained, the role of neurochemicals in microorganisms has not been 
completely understood. Moreover, recent studies are mostly concerned with a limited number of neurochemicals as exemplified by catecholamines, serotonin, and histamine. However, it is imperative that other neuroactive substances, including ptomaines (amino acid decarboxylation products) that are currently considered important regulatory agents, should be assessed with respect to their microbial effects.

The human organism is a complex "superorganism" including numerous eukaryotic, eubacterial and archaean cells, and neurochemicals function as signals that are involved in communication among them. From the perspective of human microbial ecology, estimating the regulatory and toxic effects of neurochemicals on the representatives of the gastro-intestinal tract (GIT) microbiota and their in vitro analogs is of paramount importance in neurophysiological and medical terms.

In our previous paper, some of the most important ("major") neurotransmitters of the brain, such as dopamine, norepinephrine, serotonin, and histamine, were revealed to produce a toxic effect on the bioluminescence of the biosensor strain Escherichia coli $\mathrm{K} 12 \mathrm{TGI}$ that contained the lux operon of Photorhabdus luminescencens ZMI. This effect manifested itself at high concentrations of these neurotransmitters; the same neurotransmitters except norepinephrine were found to cause bioluminescence stimulation at low (micromolar) concentrations [20].

The present work addresses the microbial effects of some other ("minor") neurochemicals that have received less attention with regard to their effects on microorganisms.

Of special interest in this context is acetylcholine (AChl). This important neurotransmitter is an evolutionarily conserved chemical that fulfills a wide variety of functions in diverse forms of life [21]. In the brain, AChl fulfils functions associated with motivation, locomotive behaviour (particularly at the initial stage of a new movement), the formation of locomotive stereotypes, memorization, learning, plasticity, and the regulation of the wakeful state; this involves the reticular formation of the brainstem and basal ganglia.

Presumably, choline, the direct precursor of acetylcholine, was employed by unicellular organisms over one billion years ago: it was converted by them into membrane phospholipids, including phosphatidylcholine [22]. Subsequently, choline was incorporated in other metabolic pathways, and also became the "raw material" for the synthesis of acetylcholine. The evolutionary prehistory of this signal substance is also highlighted by the presence of acetylcholine receptors in unicellular eukaryotes and by its regulatory effect on the conjugation process in infusorians [23] and on the growth and proliferation of Acanthamoeba sp. that possesses a homologue of the neuronal muscarine receptor for Achl and can synthesize its own AChl $[21,24]$. As for the role of AChl in prokaryotes, it is only known that $\mathrm{AChl}$ is synthesized by various bacteria, including bacilli and lactobacilli $[25$, 26].

Our work also addresses the effects of putrescine that is formed via enzymatic decarboxylation of amino acids, similar to other ptomaines (cadaverine and agmatine). Ptomaines are receiving increasing attention currently because they are considered potential hormones and/or neurochemicals. For instance, agmatine is likely to perform the function of a "non-classical" neurochemical that is synthesized in the brain, released upon membrane depolarization, and inactivated by agmatinase [27].

Some indirect data point to a possible neurochemical role of putrescine, which encourages research on its impact in microbial systems, including the human microbiota and symbiotic $E$. coli strains as its components. Nevertheless, the data on putrescine available in the literature are scanty. Putrescine together with cadaverine was detected in a number of bacterial strains that grow in pheasant meat [28]; putrescine is present in many kinds of wine [29].

The neuroactive amino acid taurine is regarded as a neurotransmitter in the literature. It is known to beneficially influence the visual sensory system and to promote athletic training. Taurine is involved in the functioning of insect nervous systems [30]. The data on its microbial effects are limited. The probiotic strain Lactobacillus casei $\mathrm{K}_{3} \mathrm{III}_{24}$ releases its micromolar concentrations into the medium $[17,18]$. The strain $L$. brevis BJ20 that grows on sea weed enriches the medium in taurine, along with other neuractive amino acids, such as glycine and $\beta$-alanine [31].

Finally, indole is of special interest because this chemical, the bicyclic backbone of the neurotransmitter serotonin, is produced by a large number of bacterial species, including those inhabiting the animal/human gut (E. coli, Bacteroides ovatis, and Clostridium bifermentus) [32]. In the gut, it is present at high concentrations (up to $0.6 \mathrm{mM}$ ) [33]. Indole inhibits biofilm formation in E. coli $[34,35]$ and, in contrast, 
stimulates this process in Pseudomonas aeruginosa and $P$. fluorescens [36]. Indole accelerates the growth of Salmonella enterica var. enteritidis [37] and stimulates the formation of antibiotic-tolerant persister cells [38].

In the present work, it was established for the first time that low concentrations of the neurochemicals putrescine, acetylcholine, and taurine, as well as of the serotonin "backbone" indole, stimulate the luminescence of the strain Escherichia coli K12 TGI that contains the lux operon of Photorhabdus luminescencens ZMI. Higher concentrations of these neurochemicals produce a weak toxic effect: they marginally inhibit the luminescence of the tested strain.

\section{MATERIALS AND METHODS}

As pointed out in our previous publication [20], a widely used biological test for the primary assessment of the effects of chemicals, their mixtures, and physical factors is based upon bacterial luminescence [39-41]. Intact cells of luminescent bacteria are used in this test, and one of its advantages is that it enables estimating the response to the tested factor from luminescence intensity that is correlated with the bacterial cells' metabolic state. In this work, we used the genetically engineered strain Escherichia coli K12 TGI as the biosensor. Its luminescent phenotype was created by cloning the lux operon of the luminescent soil bacterium Photorhabdus luminescencens ZMI in this $E$. coli strain. The strain was obtained from the Microbiology Department of the Faculty of Biology, Moscow State University. It is known as the biosensor of the Ecolyum-08 test system [41].

Growing and storing luminescent bacteria, which are generally non-pathogenic, requires conventional microbiological techniques. A convenient, fairly simple technique for the lyophilization of luminous bacteria was developed at the Department of Microbiology, Lomonosov Moscow State University.

Lyophilized bacteria are stored at $+4{ }^{\circ} \mathrm{C}$ for a long time (about a year). They represent a standard biosensor preparation, whose luminescence is measured after rehydration with cold $\left(\sim 4-12{ }^{\circ} \mathrm{C}\right)$ distilled water. Rehydrated pre-lyophilized biosensor cells are added to the experimental system immediately before the experiment.

The intensity of bacterial luminescence (counts / $\mathrm{sec}$ ) was concomitantly monitored in the control and the experimental samples with a 1251 BioOrbit
(Finland) Luminometer at room temperature (20-22 ${ }^{\circ} \mathrm{C}$ ); the biosensor was exposed to the action of the tested neurotransmitters for a period of $0.5-144$ hours.

The toxicity index $(T)$ of the neurotransmitters was determined automatically by the luminometer that was programmed to use the formula:

$\mathrm{T}=100 \times(\mathrm{lk}-\mathrm{I}) / \mathrm{lk}$, where $\mathrm{lk}$ and $\mathrm{I}$ are the illumination intensity of the control and the experimental samples, respectively. The tested neurotransmitters were classified into three groups according to their toxicity level: $T<20$, the agent is nontoxic; $T>20<50$, the agent is toxic; $T>50$, the agent is very toxic [20]. In some studies, the stimulation of luminescence of the test organism occurred, and the $T$ value was considered to be negative.

In this study, freeze-dried biosensor cells were rehydrated in cold distilled water for 30 minutes. The working suspension contained $2.3 \times 10^{7} \mathrm{cells} / \mathrm{ml}$. The density of the bacterial suspension was determined nephelometrically $(\lambda=670 \mathrm{~nm})$ with a KF77 photoelectrocolorimeter, and the number of cells per $\mathrm{ml}$ was determined by plotting a calibration curve.

Putrescine, taurine, acetylcholine, and indole (Sigma, USA) were used in this work; their concentrations were calculated based on neurotransmitter content in each of the chemicals.

To determine the bacterial luminescence of the aqueous solutions of the neurotransmitters, $0.1 \mathrm{ml}$ of the bacterial biosensor suspension were applied to 1.5 $\mathrm{ml}$ flasks; $0.9 \mathrm{ml}$ of sterile distilled water $(\mathrm{pH} 7.0)$ or of the sample solution was added to the control and the experimental flasks, respectively. The number of bacteria was determined with a KF77 photoelectrocolorimeter (Poland) at $590 \mathrm{~nm}$ based on a previously plotted standard curve.

The intensity of bacterial luminescence (counts/sec) was concomitantly monitored in the control and the experimental samples. The results of the studies were treated statistically. Three repeats of each experiment were conducted. The statistical validity of the differences between experimental and control values was assessed using the t-Student criterion.

\section{RESULTS AND DISCUSSION}

In the present work, the influence of the neurochemicals acetylcholine, putrescine, taurine, and indole on bacterial cell luminescence within the $10^{-8}$ $10^{-4} \mathrm{M}$ concentration range was investigated. The 


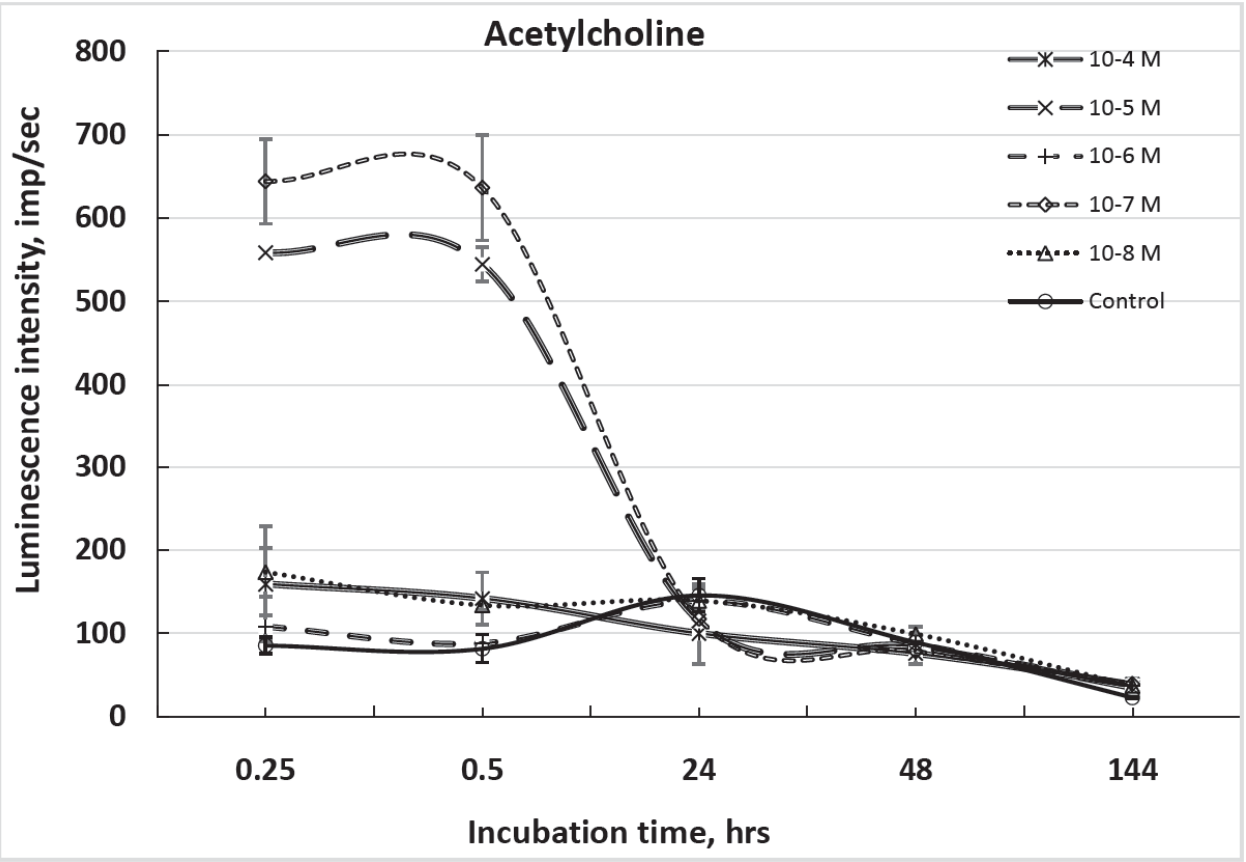

Figure 1: Effects of acetylcholine on the luminescence of the strain E. coli K12 TGI.

tested neurochemicals exerted both stimulatory and inhibitory effects on the luminescence of $E$. coli TGI cells.

Acetylcholine (Figure 1) produced a significant stimulatory effect on bacterial luminescence, an integrated metabolic activity indicator, at low concentrations $\left(10^{-7}-10^{-6} \mathrm{M}\right)$ and with short incubation times (15-30 $\mathrm{min}$ ), which is likely to be due to its regulatory, presumably receptor-dependent, influence on cell metabolism. Interestingly, higher AChl concentrations were almost without effect in this system (receptor oversaturation?). However, incubating with $\mathrm{AChl}$ for a longer time resulted in slightly inhibiting bacterial luminescence.

A very similar pattern was characteristic of the effect of taurine (Figure 2). The low concentrations that efficiently stimulated luminescence were within the $10^{-8}-10^{-7} \mathrm{M}$ range. After longer incubation times, a marginal inhibitory effect of taurine was observed.

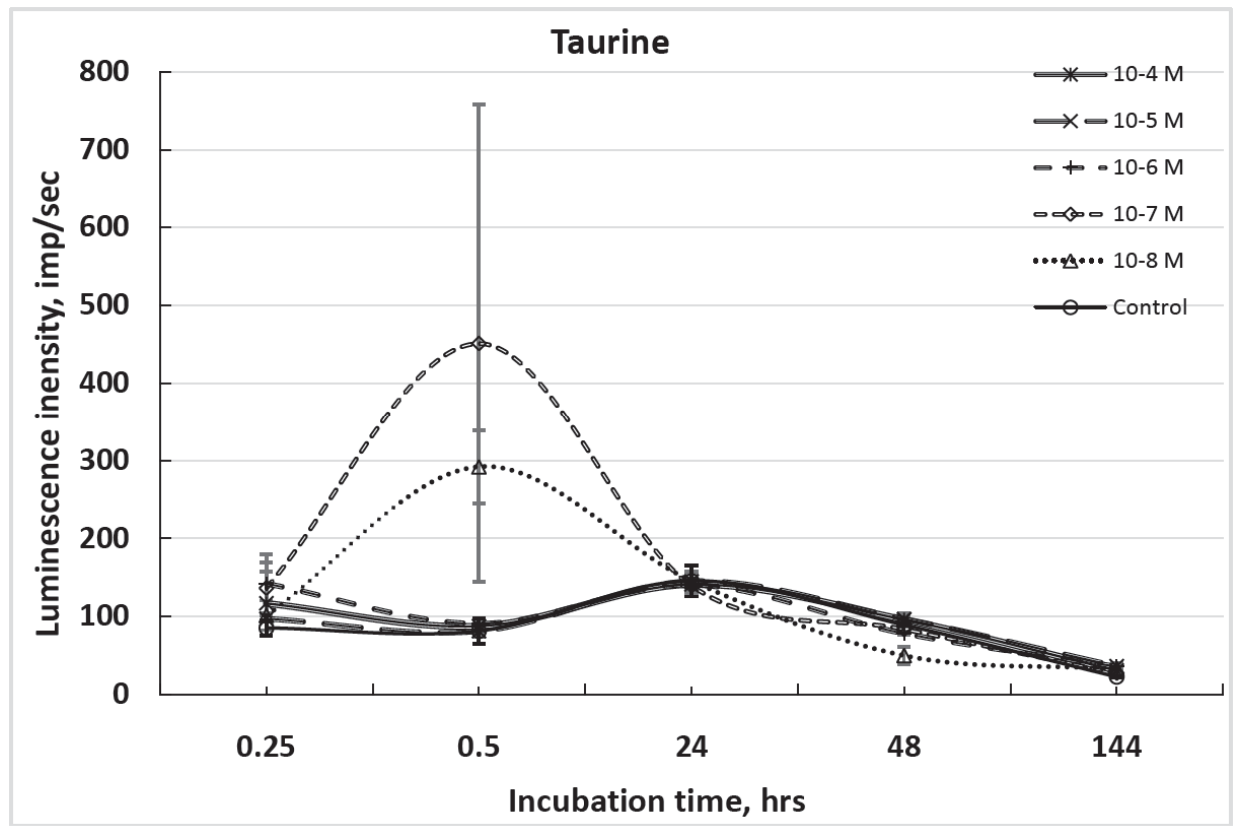

Figure 2: Effects of taurine on the luminescence of the strain E. coli K12 TGI. 


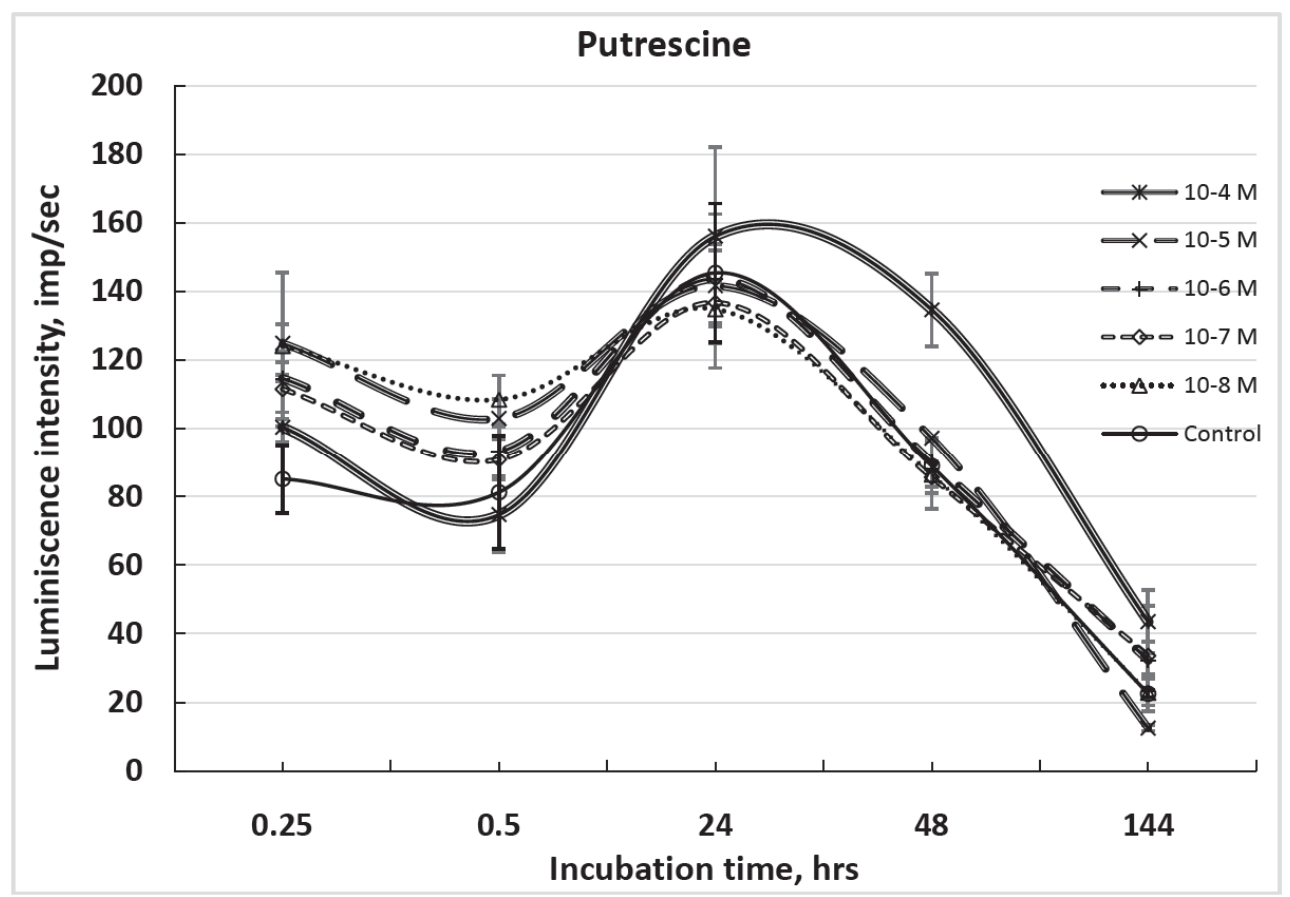

Figure 3: Effects of putrescine on the luminescence of the strain E. coli K12 TGI.

Putrescine significantly stimulated bacterial luminescence not only at low $\left(10^{-7}-10^{-6} \mathrm{M}\right)$ but also at maximally high concentrations $\left(10^{-4} \mathrm{M}\right)$; in contrast to $\mathrm{AChl}$ and taurine, the stimulatory effect increased with an increase in incubation time (Figure 3).

Indole was an efficient luminescence stimulator after 15-30 min of incubating E. coli TGI cells with it. However, a longer period of incubation resulted in luminescence inhibition. Plausibly, such transient luminescence stimulation ("negative toxicity") enables potentially pathogenic E. coli strains, e.g., O157:H7, to quit an area with a high indole concentration before the onset of the toxic effect (Figure 4). This may be the mechanism used by the symbiotic indole-producing microbiota of the gut to oust opportunistic pathogens. It is relevant that the intestinal microbiota normally produces indole concentrations as high as $0.6 \mathrm{mM}$, which might contribute to its protective action in the gut.

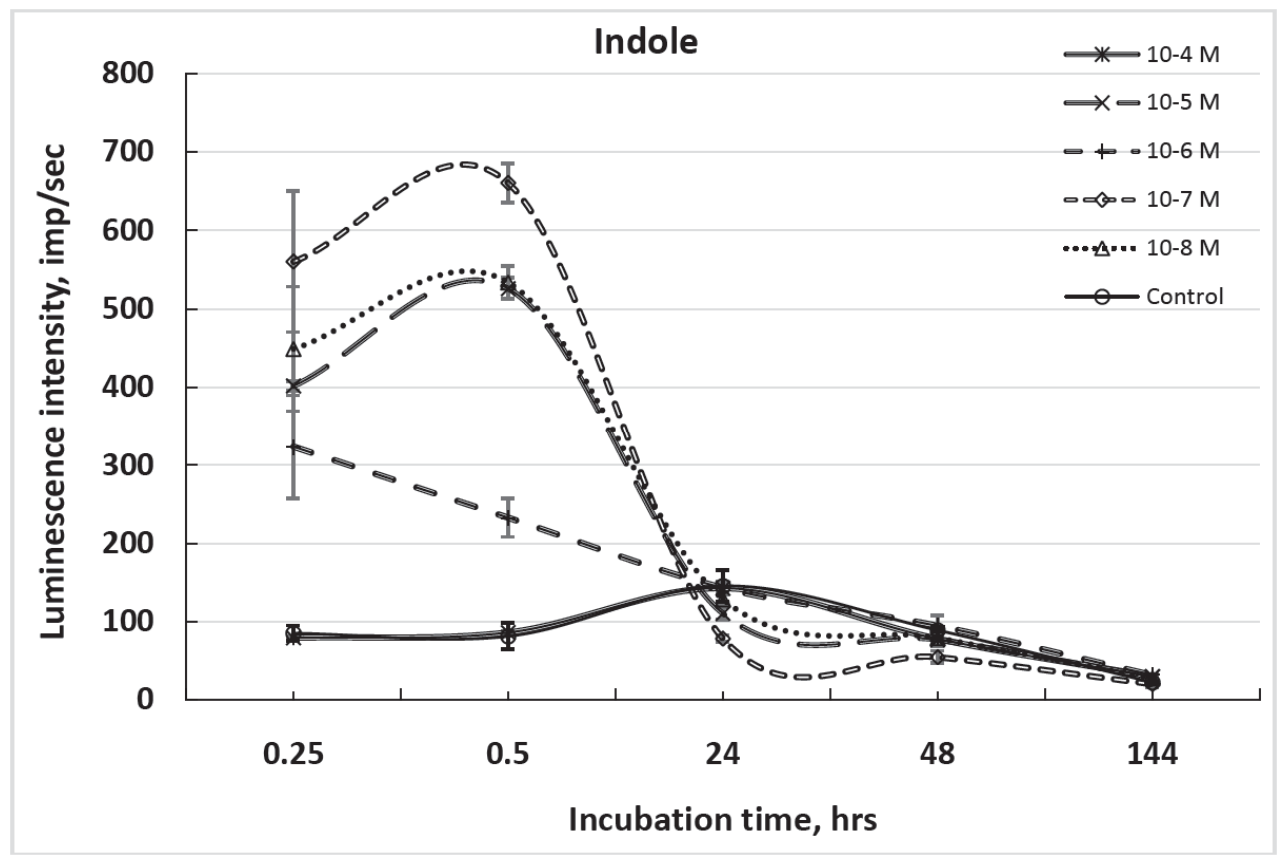

Figure 4: Effects of indole on the luminescence of the strain E. coli K12 TGI. 
Table 1: Toxicity Index of the Tested Neurotransmitters

\begin{tabular}{|c|c|c|c|c|c|c|}
\hline \multirow[t]{2}{*}{ Neurotransmitters } & \multicolumn{2}{|c|}{$\begin{array}{l}\text { Toxicity index } \\
\qquad(1 \mu \mathrm{M})\end{array}$} & \multicolumn{2}{|c|}{$\begin{array}{l}\text { Toxicity index } \\
\qquad(10 \mu \mathrm{M})\end{array}$} & \multicolumn{2}{|c|}{$\begin{array}{l}\text { Toxicity index } \\
\qquad(100 \mu \mathrm{M})\end{array}$} \\
\hline & $30 \mathrm{~min}$ & 48 hours & $30 \mathrm{~min}$ & 48 hours & $30 \mathrm{~min}$ & 48 hours \\
\hline Acetylcholine & -23.8 & 4.2 & -92.6 & 12.3 & -86.9 & 13.9 \\
\hline Taurine & -60.0 & 6.1 & -66.7 & 12.0 & -37.1 & 14.6 \\
\hline Putrescine & -31.0 & 3.8 & -34.7 & -1.3 & -17.9 & -50.6 \\
\hline Indole & -279.1 & -6.47 & -557.8 & 30.5 & 6.8 & 12.4 \\
\hline
\end{tabular}

The above plots demonstrate that all the four tested substances exhibit significant toxicity, i.e., suppress luminescence by over $20 \%$, after a long incubation period. The toxic effect develops in time and fully manifests itself after 48 hours with indole and after 24 with $\mathrm{AChl}$ and taurine. Putrescine is significantly toxic only at a concentration of $10^{-5} \mathrm{M}$ and after the maximum incubation time (144 hs). Overall, the stimulatory effect is stronger than the toxic effect. To re-iterate, the stimulatory effect manifests itself at low concentrations, which seems to suggest a regulatory (receptordependent) mechanism of action of the tested chemicals (Table 1 ).

From the table, it is evident that all the tested neurotransmitters caused the stimulation of bioluminescence after $30 \mathrm{~min}$ of incubation, i.e., the toxicity was negative. After $48 \mathrm{hs}$, all the substances developed slight positive toxicity. The error in all repeats did not exceed $5 \%$. The most pronounced toxic effect was exerted by indole.

It should be emphasized that both the stimulatory and the toxic effect can be conveniently measured with the bioluminescent strain E. coli K12 TGI containing the lux operon of Photorhabdus luminescencens ZMI. The technique of assessing the toxicity of neuroactive compounds with respect to micro-ecosystem components actually forms a part of modern bioestimation technology. In general terms, bio-estimation is aimed at diagnosing the effects of detrimental factors and normalizing the functioning of ecosystems as well as predicting the future dynamics of these effects on the ecosystems under study.

Many neurochemicals stimulate the growth of a wide range of prokaryotic species. These stimulatory effects are based on specific interactions. For instance, catecholamines bind to receptors QseB and QseC in $E$. coli (reviewed, [42]). These functional analogs of eukaryotic adrenoreceptors form a part bacterial quorum sensing systems.
Indole, apart from inhibiting potentially pathogenic microorganisms in the gut, exerts an influence on the entero-endocrine cells (EECs) of the intestinal epithelium. Indole induces EECs to produce the appetite-suppressing glucagon-like peptide (GLP-1). Owing to its similarity both to serotonin and to melatonin, indole produces the soporific effect on humans that is also exerted by high concentrations of these two chemicals [43].

The results of the experiments with the biosensor based on the lux operon-containing $E$. coli strain demonstrate that the effects of the neurochemicals can be assessed using standard biological tests. Therefore, it is to be hoped that employing such tests in basic and applied research on the role of neurochemicals in natural and human-made biological systems will help us obtain theoretically and practically (industrially) important data. Since stimulatory effects are predominantly characteristic of relatively low concentrations of the neuroactive substances, we suggest a regulatory (receptor-dependent) mode of action of the tested neurochemicals on E. coli K12 TGI, in an analogy to their impact on eukaryotic cells, including specialized nervous and immune cells. Presumably, high neurochemical concentrations exert nonspecific effects that may affect the luciferase enzyme system and/or result in uncoupling membrane phosphorylation. The second option is possible because the molecules of the tested neurochemicals contain ionizable groups in the vicinity of aromatic structures. This facilitates the transfer of electric charges and/or hydrogen ions across energytransducing membranes and the dissipation of the membrane potential.

Taken together, the results of this work indicate that the bacterial biosensor can be used to estimate the toxicity level (or, alternatively, the stimulatory effect) of the tested neurochemicals. Moreover, the data suggest that these neurotransmitters, at low (physiological) concentrations, function as sufficiently strong 
stimulators of the metabolism of the tested prokaryote and, presumably, produce specific, receptordependent, effect on its cells. Therefore, they are likely to form a part of the evolutionary conserved chemical "language" invented by living nature over a billion years ago, as the biosphere was exclusively composed of microorganisms.

\section{CONFLICT OF INTEREST DISCLOSURES}

The authors do not have any conflicts of interest.

\section{REFERENCES}

[1] Lyte M, Cryan JF. Microbial endocrinology and the microbiota-gut-brain axis. Advances in Experimental Medicine and Biology 2014; 817: 3-24.

https://doi.org/10.1007/978-1-4939-0897-4 1

[2] Lyte $M$. The role of microbial endocrinology in infectious disease. Journal of Endocrinology 1993; 137: 343-5.

[3] Lyte M. The microbial organ in the gut as a driver of homeostasis and disease. Medicinal Hypotheses 2010; 74: 634-8.

https://doi.org/10.1016/j.mehy.2009.10.025

[4] Strakhovskaya MG, Ivanova EV, Fraikin GY. Stimulatory influence of serotonin on the growth of the yeast Candida guillermondii and the bacterium Streptococcus faecalis. Microbiology 1993; 62: 46-9.

[5] Oleskin AV, Kirovskaya TA, Botvinko IV, Lysak LV. Effect of serotonin (5-hydroxytryptamine) on the growth and differentiation of microorganisms. Microbiology 1998; 67(3): 306-11.

[6] Anuchin AM, Chuvelev DI, Kirovskaya TA, Oleskin AV. Effect of neuromediator monoamines on the growth-related variables of Escherichia coli K-12. Microbiology 2008; 77(6): 758-65.

https://doi.org/10.1134/S0026261708060040

[7] Lyte M, Ernst S. Catecholamine induced growth of gram negative bacteria. Life Science 1992; 50: 203-12. https://doi.org/10.1016/0024-3205(92)90273-R

[8] Freestone PP, Lyte M. Microbial endocrinology: Experimental design issues in the study of interkingdom signaling in infectious disease. Advanced Applications in Microbiology 2008; 64: 75-108.

https://doi.org/10.1016/S0065-2164(08)00402-4

[9] Freestone PPE, Haigh RD, Lyte M. Blockade of catecholamine-induced growth by adrenergic and dopaminergic receptor antagonists in Escherichia coli 0157:H7, Salmonella enterica and Yersinia enterocolitica. BMC Microbiology 2007; 7: 8.

https://doi.org/10.1186/1471-2180-7-8

[10] Lyte M, Freestone P. Microbial endocrinology comes of age. Microbe 2009; 4(4): 169-76.

[11] Knecht LD, O'Connor GO, Mittal R, Liu XZ, Daftarian P, Deo SK, Daunert $S$. Serotonin activates bacterial quorum sensing and enhances the virulence of Pseudomonas aeruginosa in the host. European Biology and Medicine 2016; 9: 161-9. https://doi.org/10.1016/j.ebiom.2016.05.037

[12] Tsavkelova EA, Botvinko IV, Kudrin VS, Oleskin AV. Detection of neuromediator amines in microorganisms by high-performance liquid chromatography. Doklady Akademii Nauk 2000; 372: 840-2.

[13] Shishov VA, Kirovskaya TA, Kudrin VS, Oleskin AV. Amine neuromediators, their precursors, and oxidation products in the culture of Escherichia coli K-12. Applied Biochemistry and Microbiology 2009; 45(5): 494-7. https://doi.org/10.1134/S0003683809050068
[14] Malikina KD, Shishov VA, Chuvelev DI, Kudrin VS, Oleskin AV. Regulatory role of monoamine neurotransmitters in Saccharomyces cerevisiae cells. Applied Biochemistry and Microbiology 2010; 46(6): 672-7.

https://doi.org/10.1134/S0003683810060104

[15] Oleskin AV, Shishov VI, Malikina KD. Symbiotic biofilms and brain neurochemistry. Hauppauge (New York): Nova Science Publishers 2010; 58 .

[16] Kuley E, Ozogul F, Ozogul Y, Akyol I. The function of lactic acid bacteria and brine solutions on biogenic amine formation by foodborne pathogens in trout fillets. Food chemistry 2011; 129(3): 1211-6. https://doi.org/10.1016/j.foodchem.2011.05.113

[17] Oleskin AV, Zhilenkova OG, Shenderov BA, Amerhanova AM, Kudrin VS, Klodt PM. Lactic acid bacteria supplement fermented dairy products with human behavior-modifying neuroactive compounds. Journal of Pharmacy and Nutritional Science 2014; 4: 199-206.

https://doi.org/10.6000/1927-5951.2014.04.03.5

[18] Oleskin AV, Zhilenkova OG, Shenderov BA, Amerhanova AM, Kudrin VS, Klodt PM. Starter cultures of lactobacilli as producers of neuromediators such as biogenic amines and amino acids. Moleculyarnaya Promyshlennost (Russian) 2014; 9: 42-3.

[19] Yunes RA, Poluektova RU, Dyachkova MS, Klimina KM, Kovtun AS, Averina OV, Orlova VS, Danilenko VN. GABA production and structure of gadB/gadC genes in Lactobacillus and Bifidobacterium strains from human microbiota. Anaerobe 2016; 42: 1-8. https://doi.org/10.1016/j.anaerobe.2016.10.011

[20] Oleskin AV, Sorokina EV, Zarubina AP, Parkhomenko IM. Testing neurotransmitters for toxicity with a luminescent biosensor: implications for microbial endocrinology. Journal of Pharmacy and Nutritional Science 2017; 7: 88-94.

[21] Baig AM, Rana Z, Tariq S, Lalani S, Ahmad HR. Traced on the timeline: discovery of acetylcholine and the components of the human cholinergic system in a primitive unicellular eukaryote Acanthamoeba spp. ACS Chemistry and Neuroscience 2018;9(3): 494-504.

https://doi.org/10.1021/acschemneuro.7b00254

[22] Dean B. Evolution of the human CNS cholineric system: has this resulted in the emergence of psychiatric disease. Australian Journal of Psychiatry 2009; 43(11): 1016-28. https://doi.org/10.3109/00048670903270431

[23] Roshchina VV. New Trends and Perspectives in the Evolution of Neurotransmitters in Microbial, Plant, and Animal Cells. Advances in Experimental Medicine and Biology 2016; 874: 25-77.

https://doi.org/10.1007/978-3-319-20215-0_2

[24] Baig AM, Ahmad HR. Evidence of a M1-muscarinic GPCR homolog in unicellular eukaryotes: featuring Acanthamoeba spp bioinformatics 3D-modelling and experimentations. Journal of Reception and Signal Transduction Research 2017; 373: 267-75. https://doi.org/10.1080/10799893.2016.1217884

[25] Wall R, Cryan JF, Ross RP, Fitzgerald GF, Dinan TG, Stanton C. Bacterial neuroactive compounds produced by probiotics. Advanced Experimental Medical Biology 2014; 817: 221-39.

https://doi.org/10.1007/978-1-4939-0897-4 10

[26] Johnson KVA, Foster KR. Why does the microbiome affect behavior? Nature Reviews Microbiology 2018; 16: 647-55. https://doi.org/10.1038/s41579-018-0014-3

[27] Piletz JE, Aricioglu F, Cheng JT et al. Agmatine: clinical applications after 100 years in translation. Drug Discovery Today 2013; 18(17-18): 880-93. https://doi.org/10.1016/j.drudis.2013.05.017

[28] Buňkova L, Gál R, Lorencová E et al.. Microflora of farm and hunted pheasants in relation to biogenic amine 
production. European Journal of Wildlife Research 2016; 62: 341-52.

https://doi.org/10.1007/s10344-016-1008-y

[29] Doeun D, Davaatseren M, Chung MS. Biogenic amines in food. Food Science and Biotechnology 2017; 26(6): 1463-74. https://doi.org/10.1007/s10068-017-0239-3

[30] Gritsai OB. Insect behavior: the role of biogenic amines. Materials of ALTEX conference (Moscow, 2017) (in Russian).

[31] Lee BJ, Kim JS, Kang YM et al. Antioxidant activity and $\gamma$ aminobutyric acid (GABA) content in sea tangle fermented by Lactobacillus brevis BJ20 isolated from traditional fermented foods. Food Chemistry 2010; 122: 271-76.

[32] Smith EA, Macfarlane GT. Enumeration of human colonic bacteria producing phenolic and indolic compounds: effects of $\mathrm{pH}$, carbohydrate availability and retention time on dissimilatory aromatic amino acid metabolism. Journal of Applied Bacteriology 1996; 81: 288-302.

[33] Domka J, Lee J, Wood TK. YliH (BssR) and YceP (BssS) regulate Escherichia coli $\mathrm{K}-12$ biofilm formation by influencing cell signaling. Applied Environmental Microbiology 2006; 72: 2449-59. https://doi.org/10.1128/AEM.72.4.2449-2459.2006

[34] Bansal T, Englert D, Lee J, Hegde M, Wood TK, Jayaraman A. Differential effects of epinephrine, norepinephrine, and indole on Escherichia coli O157:H7 chemotaxis, colonization, and gene expression. Infectional Immunology 2007; 75 : 4597-607. https://doi.org/10.1128//AI.00630-07

[35] Lee J, Jayaraman A, Wood TK. Indole is an inter-species biofilm signal mediated by SdiA. BMC Microbiol 2007; 7: 42. https://doi.org/10.1186/1471-2180-7-42

[36] Lee J, Bansal T, Jayaraman A, Bentley WE, Wood TK. Enterohemorrhagic Escherichia coli biofilms are inhibited by 7-hydroxyindole and stimulated by isatin. Applied Environmental Microbiology 2007; 73: 4100-9. https://doi.org/10.1128/AEM.00360-07

[37] Vakhitov TY, Sitkin SI. The superorganism concept in biology and medicine. Experimental and Clinical Gastroenterology (Russia) 2014: 107(7): 72-85.

[38] Vega NM, Allison KR, Khalil AS, Collins JJ. Signalingmediated bacterial persister formation. Nature Chemical Biology 2012; 8: 431-3. https://doi.org/10.1038/nchembio.915

[39] Zarubina AP, Sorokina EV. First among equals. The bacterial luminescence test: one of the quickest and easiest bioassays. Journal of Eurasian Researcher Union Biological Series (Russian) 2015; 17(8): 161-3.

[40] Zarubina AP, Perfiliev YD, Sorokina EV, Netrusov Al. Evaluation of the properties of potassium ferrate used for water purification by luminescence bioassay. Moscow University Biological Bulletin 2016; 71(4): 226-30. https://doi.org/10.3103/S0096392516040131

[41] Zarubina AP, Gapochka MG, Novoselova LA, Gapochka LD. Effect of low intensity electromagnetic radiation on the toxicity of domestic wastewater tested with the «ecolum» test system. Moscow University Biological Bulletin 2013; 68(1): 49-52.

[42] Oleskin AV, El'-Registan GI, Shenderov BA. Role of neuromediators in the functioning of the human microbiota: "business talks" among microorganisms and the microbiotahost dialogue. Microbiology 2016; 85(1): 1-22. https://doi.org/10.1134/S0026261716010082

[43] Mazzoli R, Pessione E. The neuro-endocrinological role of microbial glutamate and GABA signaling. Frontier Microbiology 2016; 7: 1934. https://doi.org/10.3389/fmicb.2016.01934 